\title{
Produção de vídeos sobre IHC como estratégia didática no ensino remoto emergencial: um relato de experiência
}

\author{
Naiara Neves' ${ }^{1}$ João Franco ${ }^{1}$, Artur Kronbauer ${ }^{1,2}$ \\ ${ }^{1}$ Programa de Pós-Graduação em Gestão e Tecnologias Aplicadas à Educação \\ (GESTEC) - Universidade do Estado da Bahia (UNEB) - Salvador - BA - Brasil \\ ${ }^{2}$ Programa de Pós-Graduação em Sistemas e Computação (PPGCOMP) - \\ Universidade Salvador (UNIFACS) - Salvador - BA - Brasil \\ \{naiaraen, joaofranco813, arturhk\}@gmail.com
}

\begin{abstract}
This article presents an experience report in an institution of Technical Professional Education in the context of emergency remote teaching, in the academic year of 2021. The objective of the reported activity was to evaluate the contributions of video production to engagement and student autonomy from the teaching perspective. Elements of project-based learning and the inverted classroom were incorporated in the methodological design of the experience. The project's products were videos created by student teams and posted on YouTube. The results showed the relevance of learning environments for support and dynamization in remote teaching and the need for teaching articulation with the context and pedagogical intentions regarding the use of digital technologies above all.
\end{abstract}

Resumo. Este artigo apresenta um relato de experiência em uma instituição de Educação Profissional Técnica no contexto do ensino remoto emergencial, no ano letivo de 2021. O objetivo da atividade relatada foi avaliar, a partir da ótica docente, as contribuições da produção de vídeos para o engajamento e autonomia dos estudantes. No desenho metodológico da experiência, foram incorporados elementos da aprendizagem baseada em projetos e da sala de aula invertida. Os produtos do projeto foram vídeos criados por equipes de estudantes e publicados no YouTube. Os resultados evidenciaram a relevância de ambientes de aprendizagem para apoio e dinamização no ensino remoto e, sobretudo, da necessidade de articulação docente com o contexto e a intencionalidade pedagógica quanto ao uso das tecnologias digitais.

\section{Introdução}

Com inúmeros esforços, no último ano, o Brasil e o mundo trabalharam para conter os efeitos da pandemia de Covid-19, causada pelo novo coronavírus. Medidas como o uso obrigatório de máscaras e o distanciamento social ajudam a conter os avanços da doença, cujos impactos atravessam as formas e os meios de conviver, consumir e produzir, vender e, inclusive, educar.

Neste cenário, em caráter excepcional, o Ministério da Educação (MEC) autorizou a substituição das aulas presenciais pelo ensino por mediação tecnológica, por meio da Portaria $n^{\circ} 343$, de 17 de março de 2020. Essa migração do ensino presencial para o ensino remoto emergencial, em decorrência da pandemia, suscitou de docentes mudanças nos métodos de ensino - uma vez que não basta reproduzir a aula ministrada no presencial no contexto remoto, já que as condições impostas são diferentes - , ao mesmo tempo que exigiu dos estudantes esforço no desenvolvimento da autonomia. 
Face à conjuntura exposta, este artigo apresenta uma experiência pedagógica baseada na produção de vídeos como estratégia para promover o engajamento de estudantes do curso Técnico em Desenvolvimento de Sistemas, durante as aulas remotas do primeiro semestre de 2021, no município de Salvador - Bahia. Busca-se responder à seguinte questão: Como potencializar a experiência dos alunos em aulas remotas na disciplina Interface Homem-computador? Isto posto, pretende-se analisar, a partir da experiência aqui exposta, se a produção de vídeos contribuiu para o engajamento e autonomia dos estudantes, na dinâmica desenhada para o desenvolvimento da disciplina.

Para alcançar este objetivo, o artigo está organizado nas seguintes seções: a Seção 2 indica os materiais e métodos para a construção deste trabalho, trazendo também a caracterização da disciplina e da turma; a Seção 3 traz o relato da experiência em questão, bem como as discussões concernentes ao tema, de acordo com o referencial teórico-metodológico adotado. Finalmente, a Seção 4 traz as considerações finais.

\section{Materiais e Métodos}

Esta pesquisa é de natureza aplicada, visto que "é conduzida em um campo de prática comum e se preocupa com a aplicação e desenvolvimento de conhecimento baseado em pesquisa sobre essa prática" [Mcmillan \& Schumacher 2014]. A abordagem é de ordem qualitativa, buscando descrever como os estudantes experimentaram a prática desenvolvida e fornecendo feedbacks ao longo do desenvolvimento até a conclusão. Também tem característica exploratória, visto que há uma busca por mais familiaridade com o assunto estudado, aprimorando as hipóteses e ideias existentes.

\subsection{Caracterização do curso e da disciplina}

A componente curricular Interface Homem-Computador (IHC) faz parte do currículo do Curso de Educação Profissional Técnica de Nível Médio em Desenvolvimento de Sistemas. Das mil horas que compõem o curso, o componente tem carga horária de 48 horas, e está alocado no segundo dos três módulos nos quais a matriz curricular do curso é organizada.

A ementa do componente curricular propõe o desenvolvimento de capacidades técnicas para projetar e desenvolver interfaces de sistemas utilizando técnicas, respeitando normas e recomendações de usabilidade, de acordo com padrões de qualidade, robustez, integridade e segurança da informação. No período aqui relatado, o componente foi estruturado seguindo a sequência didática ilustrada abaixo:

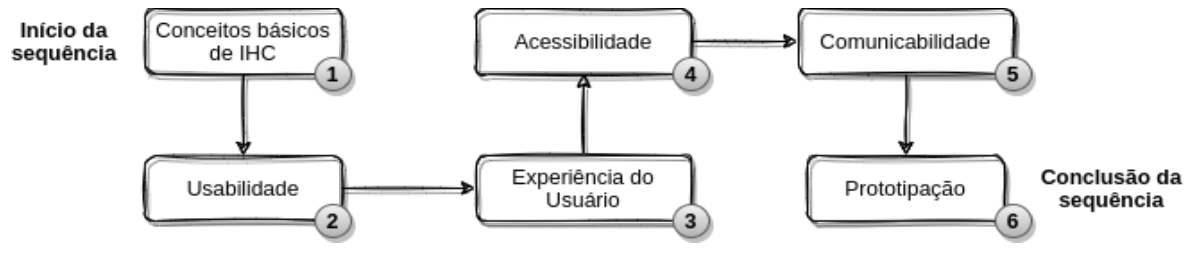

Figura 1. Esquema do componente curricular IHC no semestre 2021.1 


\subsection{Caracterização dos participantes}

A turma que realizou o projeto era composta por 54 alunos. A participação na pesquisa foi voluntária e contou com a adesão de cinquenta alunos para apresentar o grau de satisfação com o projeto e um comentário livre. O questionário foi disponibilizado através do Google Forms e divulgado no Mural do Google Classroom para toda turma.

A seção inicial do questionário contemplou questões em relação à idade, ao gênero e ao tempo de uso do YouTube. Estas perguntas foram feitas com a intenção de analisar o perfil dos participantes. Diante disto, os resultados obtidos em relação a estas perguntas foram: a) A média aritmética da idade dos participantes é de 18 anos. b) A porcentagem de participantes do gênero feminino foi igual a $22 \%$ e do gênero masculino 78\%.c) A média aritmética de tempo de uso do YouTube é de 6,3 anos.

Após a sequência didática com aulas expositivas, seguindo o ilustrado na Figura 1, exemplos práticos e gamificação com o uso do Kahoot para revisão dos conceitos após cada tópico, a justificativa do projeto, objetivo geral, específicos e os critérios de avaliação foram apresentados aos discentes

\section{Resultados e Discussões da Experiência: a Materialidade da Prática}

Kronbauer (2020) indica propostas metodológicas para ajudar os professores a colocar em prática bons desenhos metodológicos como forma de socializar experiências oriundas da educação a distância $(\mathrm{EaD})$, cibercultura e espaços colaborativos.

A experiência consistiu na elaboração e publicação de um vídeo no YouTube por equipes compostas por cinco a seis integrantes apresentando os critérios de qualidade em IHC vistos durante o semestre com foco nas ferramentas tecnológicas mais utilizadas pela turma durante as aulas remotas. As equipes tiveram o prazo de um mês para a elaboração dos vídeos e, ao longo deste tempo, semanalmente algumas equipes eram selecionadas para apresentação dos resultados parciais e orientação. Assim, seguindo a classificação de Bender (2014) a respeito de elementos da Aprendizagem Baseada em Projetos (ABP), houve feedback formativo e somativo.

No primeiro caso, "a avaliação acontece durante o processo de ABP para ajudar os alunos a formar ou reorientar seus trabalhos conforme necessário"; no segundo, "a avaliação final acontece ao término do projeto" [Bender 2014]. Neste caso, o papel docente foi de curadoria; o desenho metodológico buscou estimular a aprendizagem entre os pares e "ajudar os aprendizes a ampliar a visão de mundo que desenvolveram nos percursos individuais e grupais, levando-os a novos questionamentos, investigações, práticas e sínteses” [Moran 2018].

Além do breve contexto histórico da ferramenta de estudo selecionada, cada equipe, conforme a sequência didática, deveria atingir alguns objetivos, descritos no Quadro 1, para cada critério de qualidade. Cada critério deveria ser evidenciado com imagens ou vídeos e devidamente explicado a partir das discussões realizadas em equipe. As ferramentas foram listadas conforme a sugestão da turma e as selecionadas para análise foram: Discord, WhatsApp, Microsoft Teams, Twitch, Duolingo, Spotify, 
Google Classroom e Telegram. Todos os vídeos da turma foram reunidos e divulgados através de uma playlist ${ }^{1}$ do YouTube, organizada pela docente.

\begin{tabular}{|l|l|}
\hline \multicolumn{1}{|c|}{ Critério } & \multicolumn{1}{c|}{ Objetivo } \\
\hline Usabilidade & Avaliar conforme as 10 Heurísticas de Nielsen \\
\hline Experiência do Usuário & $\begin{array}{l}\text { Apresentar o relato do usuário em canais como a Google Play Store, } \\
\text { Reclame Aqui ou similar } \\
\text { Identificar duas leis de Experiência do Usuário }\end{array}$ \\
\hline Acessibilidade & Apresentar recursos de acessibilidade e/ou tecnologia assistiva \\
\hline Comunicabilidade & Identificar e analisar o significado das cores, fontes e mensagens \\
\hline
\end{tabular}

Quadro 1. Critérios de qualidade em IHC e objetivos relacionados na atividade.

Bender (2014) destaca que os formatos das avaliações adotados pelos docentes abrem espaço para a criatividade do professor. Assim, é possível utilizar avaliações entre os próprios estudantes, que avaliam as produções uns dos outros. Partindo desta perspectiva, após a criação da playlist, os alunos foram convidados a assistir às produções das demais equipes no prazo de uma semana para futura discussão em sala no Google Meet sobre cada ferramenta estudada, bem como para avaliação somativa da docente regente. A avaliação entre os pares ocorreu na etapa final da disciplina, descrita na Figura 2 como "Avaliação e discussão".

No dia da avaliação, foi disponibilizado um formulário para que os estudantes de forma individual pudessem registrar como foi a experiência com a execução desta prática e também um espaço para que todas as equipes pudessem comentar oralmente sobre o desenvolvimento do vídeo e a produção feita pelas outras equipes.

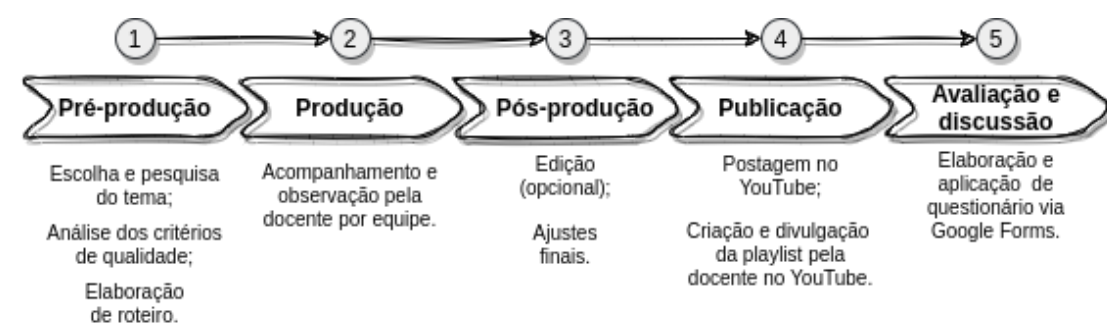

Figura 2. Etapas da experiência: da pré-produção à avaliação e discussão dos vídeos por pares.

Da perspectiva docente, o projeto atingiu o objetivo de engajar a turma, o que foi reforçado nas respostas ao questionário. Em um dos comentários, um dos discentes comentou que "realmente ajuda o aluno a praticar os conceitos ensinados em sala de aula". Outro estudante afirmou: "No início achei que seria algo complicado a se fazer, mas ao iniciar o projeto foi maravilhoso. Além de aprender os assuntos mais na prática do que apenas na teoria". A média de visualizações de cada vídeo na playlist foi 61 e reforça o sucesso e apreciação dos alunos. Diante do questionamento "Você ficou satisfeito ao usar o YouTube atrelado ao Projeto?", 94\% das respostas foram afirmativas (Sim).

${ }^{1}$ Disponível para acesso no link: https://bit.ly/3kkUMPG. 


\section{Considerações finais}

Este artigo buscou apresentar um relato de experiência de produção de vídeos para a plataforma YouTube, com uma turma de um curso técnico em Desenvolvimento de Sistemas, durante as aulas remotas no ano letivo de 2021. A sequência didática apresentada vem como uma sugestão de ação que busca promover a integração entre teoria e prática, bem como, a diminuição da fragmentação da abordagem dos conteúdos propostos no componente curricular IHC.

Diante das considerações de Moran (2018) e Bender (2014), torna-se perceptível a necessidade de articulação entre o saber pedagógico e o domínio dos artefatos tecnológicos, do ponto de vista docente e discente, para concepção de tecnologias educacionais com a participação interativa entre estes atores. Como resultado, é possível impulsionar experiências mais motivadoras e atraentes, em função da participação ativa dos atores do processo educacional.

A experiência também destacou a possibilidade de articulação de projetos de ensino tendo o YouTube como principal recurso pedagógico. Neste sentido, a incorporação de elementos da ABP atingiu os objetivos propostos, contribuindo à formação técnica dos estudantes, organizando discussões e práticas sobre Usabilidade, Experiência do Usuário, Comunicabilidade e Acessibilidade. Espera-se que futuramente ações como essa sejam perpetuadas em outros componentes curriculares, em busca da promoção da articulação entre teoria e prática e da diversificação de recursos de apoio à aprendizagem responsável e condizente com o projeto pedagógico da instituição.

\section{Referências}

Bender, W. N. (2014). Aprendizagem baseada em projetos: educação diferenciada para o século XXI. Porto Alegre: Penso.

Kronbauer, A. H. (2020). Um desenho metodológico para engajar e motivar os alunos nas aulas remotas na pandemia do Covid-19, 8(3), 611-626. https://doi.org/10.17564/2316-3828.2020v8n3p611-626.

McMillan, J. H., \& Schumacher, S. (2014). Research in Education: Evidence-Based Inquiry, 7th edition. MyEducationLab Series. Pearson Education.

Moran, J. (2018). Metodologias ativas para uma aprendizagem mais profunda. Metodologias ativas para uma educação inovadora: uma abordagem teórico-prática. Porto Alegre: Penso, 02-25.

Nielsen, J. (1994). “10 Usability Heuristics for User Interface Design”, https://www.nngroup.com/articles/ten-usability-heuristics/.

Norman, D. A. and Nielsen, J. (2016). "The Definition of User Experience", https://www.nngroup.com/articles/definition-user-experience/. 